УДК 539.37, 535.4

Зиновьев В.Б., Шведов В.Н., Ким Л.И. ЭКСПЕРИМЕНТАЛЬНОЕ ОПРЕДЕЛЕНИЕ ГЛУБИНЫ ЗАБИВКИ НАГЕЛЕЙ ОГНЕСТРЕЛЬНЫМ СПОСОБОМ

Новосибирский государственный архитектурно- строительный университет, Россия Новосибирск, ул. Ленинградская 113, 630008

Zinoviev V.B., Shvedov V.N., Kim L.I.

EXPERIMENTAL DETERMINATION OF DEPTH

NAGEL SCORING GUNSHOT WAY.

Novosibirsk State University of Architecture and Civil Engineering (Sibstrin) 113 st. Leningradskaj, Novosibirsk 630008, Russia

Аннотащия. Экспериментальным путем исследована зависимость глубинь забивки нагелей от влажности древесины и мощности патронов. Предложена экспоненциальная аппроксимащия данной зависимости.

Ключевые слова: Соединение деревянных элементов, нагели крестообразного сечения, огнестрельная забивка.

Annotation. Experimentally, the dependence of the depth of plugging pegs of wood moisture and capacity cartridges. An exponential approximation of this dependence.

Keywords: Connection of wooden elements, nageli cross-shaped cross-section, a gunshot pile.

\title{
Вступление.
}

Будучи в лидерах мирового запаса лесных ресурсов, в деревянном домостроении наша страна катастрофически отстает в области деревянного домостроения от западных стран. Например, в Северной Америке и Скандинавских странах на $1 \mathrm{~m}^{2}$ построенного жилья приходится 0,6-0,7 $\mathrm{m}^{3}$ деревянных материалов. В России же этот показатель только $0,05 \mathrm{~m}^{3}$ (и это с 
учетом развития отрасли на протяжении последних 5-ти лет!). Во всех развитых странах основная целевая аудитория для деревянного домостроения - средний класс. В России же древесина относится к материалам для элитного новостроя. Цена на оцилиндрованные бревна, клееный брус, массивную клеенную древесину - материалы всем знакомые и проверенные временем действительно высока, a новым технологиям большая часть населения попросту не доверяет.

Основные мотивы, согласно которым приоритеты российских потребителей склоняются деревянному домостроению: экологичность - дерево не только считается самым здоровым стройматериалом для дома, но и наиболее комфортным в плане создания физического и психологического комфорта для человека; высокая теплоемкость - правильно сконструированный деревянный дом позволяет сэкономить средства на обогреве помещения; потенциальная доступность древесины как сырьевой базы, благодаря обширным ресурсам страны и программе государственного развития отрасли; короткий срок строительства зданий, по сравнению с железобетонными и кирпичными домами.

Это направление должно затронуть не только техническое обеспечение производства, а и разработку новых методов ведения строительства.

\section{Обзор литературы.}

При соединении строительных конструкций из древесины часто применяют нагели круглого сечения, устанавливаемые в предварительно просверленные отверстия [1]. Это соединение имеет как преимущества, так и недостатки, основным из которых является высокая трудоемкость.

Одним из перспективных направлений является применение нагелей крестообразного сечения, забиваемых огнестрельным способом при изготовлении или ремонте деревянных конструкций. Для огнестрельной забивки таких нагелей возможно использование отечественных строительномонтажных пороховых инструментов, например, строительно-монтажный пистолет ПЦ 52-1, ПЦ-84 и его модификации. При этом необходимо 
модернизировать пистолет, изменив форму наконечника и направителя. Применение монтажных пороховых инструментов обладает неоспоримыми преимуществами в сравнении с другими инструментами, применяемыми в аналогичных случаях: широкая маневренность, отсутствие потребности в посторонней энергии (сжатый воздух или электроэнергия), что уменьшает трудоемкость изготовления узловых соединений, деталей и, как следствие, общую стоимость возводимых конструкций. Применение огнестрельного способа забивки нагелей позволяет изготовить и смонтировать строительные конструкции в кратчайшие сроки, например, при ремонтных или восстановительных работах.

В работах [2,3] с помощью оптических методов исследования деформированного состояния [4- 8] определялось допустимое расстояние между осями нагелей. При этом предполагалось, что возмущение, вызванное забивкой нагеля, убывает по экспоненциальному закону [9]. Однако, в работах не рассматриваются критерии выбора мощности патрона в зависимости от необходимой глубины забивания нагеля, влажности древесины и размеров поперечного сечения крестообразного нагеля, что препятствует широкому внедрению данного метода в строительную практику.

\section{Входные данные и методы.}

В строительно-монтажных пистолетах российского производства используются патроны двух типов: с шифром Д (длинные); с шифром К (короткие). По весу порохового заряда и мощности строительно-монтажные патроны шифров К и Д подразделяются на 4 номерных типа. Самому мощному в обеих группах присвоен красный цвет, самому слабому - белый.

Энергоотдача возрастает с увеличением номера типа, так для патрона К1 энергоотдача составляет 548 Дж., а для К4 - 795 Дж., а для патрона Д1 - 874 Дж и для патрона Д4 - 1174 Дж. В ходе предварительных испытаний было определено, что мощности патронов К1 - К3 недостаточна для забивки нагелей, поэтому испытания проводились и использованием патронов К4, Д1, Д2, Д3, Д4. 
Забивание производилось четырех типа размеров прямолинейных нагелей крестообразного поперечного сечения с габаритными размерами поперечного сечения 10x10 мм, 12×12 мм, 16x16 мм, 22х22 мм. Нагели имели ножевую коническую заточку. Во всех случаях толщина ребра креста в поперечном сечении составляла 3 мм. При забивании брус укладывался на горизонтальную жесткую поверхность, модернизированный строительно-монтажный пистолет с забиваемым нагелем устанавливался вертикально к поверхности и прижимался максимальным усилием человека. Величина вертикальной нагрузки не контролировалась. Каждый тип нагеля отстреливался, минимум, десять раз. Результаты испытаний, резко отклоняющиеся от средних величин (обычно в меньшую сторону), отбрасывались.

В таблице 1 приведены результаты экспериментальных исследований по определению глубины забивания нагеля в зависимости от мощности патрона, влажности древесины и габаритных размеров нагеля. Данные, приведенные в таблице, являются среднеарифметическими значениями по результатам, минимум, десяти испытаний.

Таблица 1

\begin{tabular}{|c|c|c|c|c|c|c|c|}
\hline $\begin{array}{c}\text { Габаритные } \\
\text { размеры } \\
\text { сечения }\end{array}$ & \multicolumn{6}{|c|}{ Глубина забивки нагеля в зависимости } \\
\cline { 2 - 8 } нагеля мм & $\mathrm{W}=25 \%$ & $\mathrm{~W}=15 \%$ & $\mathrm{~W}=8 \%$ & $\mathrm{~W}=8 \%$ & $\mathrm{~W}=25 \%$ & $\mathrm{~W}=15 \%$ & $\mathrm{~W}=8 \%$ \\
Д1 & Д2 & Д3 & Д4 & $\mathrm{K} 4$ & $\mathrm{~K} 4$ & $\mathrm{~K} 4$ \\
\hline $10 \times 10$ & 10.5 & - & - & - & 9.7 & 8.5 & 7.0 \\
\hline $12 \times 12$ & 8.0 & 10.0 & - & - & 7.0 & 6.0 & 5.5 \\
\hline $16 \times 16$ & 5.0 & 6.0 & 7.0 & 10.0 & - & - & - \\
\hline $22 \times 22$ & 3.0 & 5.0 & 6.0 & 8.0 & - & - & - \\
\hline
\end{tabular}

При обработке полученных результатов было предположено, что глубина забивания экспоненциально убывает с увеличением габаритного размера нагеля:

$$
S=S_{0} e^{-\frac{H}{\lambda}}
$$


Здесь $S$ - глубина забивки нагеля; $H$ - габаритный размер нагеля; $S_{0}$ константа, зависящая от влажности древесины; $\lambda$ - постоянная затухания; Е$\ldots$ ?..?

Для определения величин $S_{0}$ и $\lambda$ данные, полученные для древесины с влажностью 25\% и 15\% и патронов Д1 и Д2, были построены в логарифмическом масштабе. По оси абсцисс откладывались величины габаритных поперечных размеров нагеля, по оси ординат натуральный логарифм от глубины забивания. Оказалось, что это две параллельные прямые. По углу наклона прямых было определено $\lambda$, равным примерно 9 см. Используя полученную величину, были вычислены значения $S_{0}$ для влажности $25 \%$ и 15\%. Для влажности 25\% $S_{0}=31$ см., а для влажности $15 \% \quad S_{0}=39$ см. Полученные результаты позволяют прогнозировать глубину забивания нагелей, размеры которых не приведены в таблице. Так, нагель с габаритным размером 15 мм в древесину влажностью 15\% будет забит патроном Д2 на глубину порядка 7,5 см, а нагель габаритным размером 10 мм, при тех же условиях, будет забит на 13,5 см.

Следует отметить, что полученные результаты, вследствие небольшого количества экспериментальных данных, носят предварительный характер. Кроме того, при проведении испытаний было замечено, что большое влияние на глубину забивки нагеля оказывает сила, приложенная к рукоятке монтажного пистолета. C точки зрения экспериментатора, уменьшение нагрузки на пистолет при забивке нагеля приводило к уменьшениям глубины забивания. Эти результаты были исключены из использованных данных, но сформировали направление дальнейших исследований.

Литература:

1. Попов А.М., Зиновьев В.Б., Сподарева Л.А. Деформированное состояние мостовых конструкций вблизи нагеля круглого сечения.транспорта Сибири и Дальнего Востока. 2015. № 3. С. 77-80. 
2. Зиновьев В.Б., Шведов В.Н., Попов А.М. О расстановке нагелей крестообразного сечения в соединении деревянных элементов.- Известия высших учебных заведений. Строительство. 2012. №3. С.127-131.

3. Столповский Г.А., Жаданов В.И., Аркаев М.А., Зиновьев В.Б. Особенности расстановки витых стержней в узловых сопряжениях деревянных конструкций. - Известия высших учебных заведений. Строительство. 2014. №5 (665). C.91-97.

4. Жилкин В.А., Зиновьев В.Б. Возможные методы расшифровки голографических интерферограмм, записанных у поверхности металлизированных растров. В сборнике: Механика деформируемого тела и расчет транспортных сооружений. Новосибирск, 1980. С.113-120.

5. Жилкин В.А., Зиновьев В.Б., Горбунова Т.В. Исследование анизотропных задач механики деформируемых тел методом голографического муара.- Механика композитных материалов. 1983. № 2. С. 341-347. 6. Жилкин В.А., Зиновьев В.Б. Расшифровка интерференционных картин в методе голографического муара. -Журнал технической физики. 1986. Т. 56. № 1. C. 113.

7. Gerasimov S.I., Zhilkin V.A., Zinoviev V.B. Superposed holographic interferometers - recent developments. В книге: Lasers and their application IV National conference and technical exhibition with international participation: abstracts. 1990.C.104-105

8. Жилкин В.А., Зиновьев В.Б., Герасимов С.И. Моделирование элементов строительных конструкций с использованием накладных голографических интерферометров. В книге: Экспериментальное исследование инженерных сооружений (методы, приборы, оборудование, метрологическое обеспечение). Тезисы докладов VII Всесоюзной конференции. 1991. С. 258.

9. Жилкин В.А., Зиновьев В.Б. Определение зоны краевого эффекта с помощью метода голографического муара.- Прикладная механика и техническая физика. 1986. Т. 27. № 5 (159). С. 132-135. 